hollow gesture. Yet it is remarkable that even so, scientific research is mostly exempt.

Whether Congress will approve the budget is the question, given how little the president and Congress have managed to get done together, even before the Democrats lost their overwhelming majority in the Senate following last month's Massachusetts election victory by a Republican candidate. However, if the budget goes through as something resembling Obama's proposal, funding levels for basicresearch agencies would stay on track for a doubling over ten years. Before researchers begin rejoicing at the prospects of more money for grants, they would be wise to remember that the economic downturn continues to resonate in many areas.

Universities continue to suffer record drops in their endowments, with many researchers at public and private universities going on involuntary unpaid leave. Competition for graduate-student and postdoc places is fierce, with many qualified students being turned away. This is particularly worrying because training the next generation of scientists and engineers is one of the primary themes of the Obama administration. In announcing his budget this week, he argued again that investment in scientific research would lead to jobs and new industries down the line. That may well turn out to be true but, in the short term, students and young researchers are still feeling the pinch.

Future investment from the private sector also remains unknown. US venture-capital spending plunged by $31 \%$ from 2008 to 2009, according to market tracker Dow Jones VentureSource, although the biotech sector emerged the least scathed, with 'only' an $11 \%$ drop. It remains to be seen how venture capitalists and larger corporations that survive the economic downturn will restructure and rethink their investments in research and development.

Nevertheless, researchers can be relieved at the proposed increases in the presidential budget. But they need to be aware that expectations will be high for delivering on this largesse, and for accountability.

One form of accountability lies in the administration's laudable effort for government transparency. To this end, research agencies can be supportive by posting high-value data sets from their grantees on Data.gov. As of this week, there remained much opportunity for improvement; agencies were trickling out fascinating but stubbornly limited data sets, such as the number of Freedom of Information Act requests received by the National Science Foundation last year. Full transparency will help to inform the American people as to whether their tax money is being best spent.

Another more contentious form of accountability lies in the extent to which the science budgets are deployed on research that is intended to address short-term problems. Research communities can anticipate pressures to move the balance of research effort in that direction. However researchers respond, they will need collectively to go to unprecedented lengths to convince the nation that the president's trust was not misplaced.

\section{Back to books}

\section{Researchers should be recognized for writing books to convey and develop science.}

$\Lambda$ s the era of the electronic book dawns, perhaps hastened by Apple's much-touted iPad, researchers should prime themselves to take advantage of the spacious book format. Unlike a tweet, blog or research paper, a good book offers space to breathe, to contemplate complex ideas and to convey a mode of thinking. But most scientists don't think of writing one, and, if they do, they do it in secret.

In the hope that this might change, this week we kick off a series of weekly interviews with science book authors in Nature's Books \& Arts section. Peter Atkins reveals the hard work behind a successful textbook (see page 612); Carl Zimmer will highlight how passion is essential for popular science; David Brin will reveal that criticism improves fiction writing; Georgina Ferry will share research tips for biographies; and Joanna Cole will explain how to convey science to children.

Such advice is timely. The role of textbooks in handing down the tenets of disciplines is changing as online components take over from printed text. Atkins acknowledges that the extra effort of producing layers of educational material for the web today makes writing a textbook daunting. Most researchers, he admits, would not be able to devote so much time to translating their work for students. Covering broad core subjects such as general chemistry would be nigh on impossible to do in snatched moments. He is lucky that, following his publishing success, his department supported his shift to full-time writing and teaching. Many would see their careers set back if their research was displaced.

Textbook workloads could be eased in the online environment by being written in modules by conglomerates, in a 'wiki' model of education. Such accumulations of knowledge are extensive, valuable and democratic. But they move away from the classic idea of a textbook as one person's view of a field, accumulated through personal experience, years of research and face-to-face interactions with students.

Beyond textbooks, the human side of research deserves exposure as much as it ever has, through popular science accounts, biography and fiction. Although the publishing markets today apply a narrow filter, future readers can expect to enjoy access to a wider range of topics through e-books, which are easier to distribute and lack the overheads of print. As a specialist area, science stands to benefit.

Rather than limit scientific discourse to curt journal papers, researchers should embrace the book as another means of expressing not only their insights but also their visions. Through the various styles of writing, all aspects of science can be explored and laid out for posterity and learning. The expansiveness of a book allows sophisticated arguments to be put forward and widely debated; new ideas that cross disciplinary boundaries can more readily be shared and worked through.

But if this exhortation is to have any traction, the effort and skill required to write a book needs to be rewarded in the career recognition of scientists who devote time to mastering the art to good effect - a recognition that is commonplace in the social sciences and humanities. It is time to bring the book back into the science mainstream. This needn't be a mass movement: just a dedicated few, but more of them, could fulfil the reasonable hope that their books will inspire a new generation. And they should be encouraged to do so. 